\title{
Elastic properties of the layers of three-layer particleboards
}

\author{
Arnold Wilczyński • Marek Kociszewski
}

Received: 21 May 2010 / Published online: 12 November 2010

(C) The Author(s) 2010. This article is published with open access at Springerlink.com

\begin{abstract}
Elastic properties of the face and core layers of commercial three-layer particleboards were examined. The method of compressing the block specimens glued from strips of layers separated from boards, and measuring specimen deformations by the electric resistance strain gauge technique was used. The layers were assumed to be orthotropic materials and the set of elastic constants were determined for both the face and core layers.
\end{abstract}

\section{Elastische Eigenschaften der einzelnen Schichten dreischichtiger Spanplatten}

\section{Introduction}

Typical particleboards are three-layer boards which consist of a central layer (core) and two outer layers (faces). Structures of these layers differ markedly. The face layers, made of smaller chips with a higher resin content, have a greater compaction ratio and density, and in consequence better mechanical properties.

Data on the mechanical properties of entire particleboards are not always sufficient. Moreover, learning these data for the particleboard layers may be in some cases very desirable. Particularly, knowledge of elastic properties of these layers may be useful for more rational designing of structural members made of particleboards and for analyzing stresses and deformations occurring in these members.

Many studies have been carried out with regard to elastic properties of particle boards. However little has been done

A. Wilczyński · M. Kociszewski ( $₫)$

Institute of Technology, Kazimierz Wielki University,

Chodkiewicza 30, Bydgoszcz 85-064, Poland

e-mail: kocisz@ukw.edu.pl in respect of the elastic properties of the particleboard layers. Keylwerth (1958) studied the Young's moduli in tension and compression parallel to the layer plane for the face and core layers separated from the board, and the modulus of elasticity in bending and shear modulus in the layer plane but only for the core layer. Geimer et al. (1975) determined the Young's moduli of the face and core layers separated from the board using a tensile test in the direction parallel to the layer plane, and the shear modulus of the core layer in the plane perpendicular to the layer by an interlaminar shear test. Dueholm (1976) assessed the Young's moduli of the particleboard layers determining the face layer modulus by an indirect method consisting of comparing the stiffness of the raw (unsanded) with sanded specimens. The depth of sanding was equal to the thickness of the face layer. He used a static tensile test and two dynamic tests. The moduli of elasticity of the layers were also investigated by May (1983), who determined the face layer modulus in a similar indirect way by employing a static bending test. In turn $\mathrm{Bu}-$ cur et al. (1998) determined the Young's moduli of the face and core layers in the direction parallel to the layer plane using the ultrasonic method and dynamic mechanical analysis technique. Wilczyński and Kociszewski (2007) studied the layer moduli of elasticity in bending for three directions: the mat forming direction, the direction perpendicular to it, and the direction perpendicular to the layer plane, using the specimens glued from layers separated from boards.

The aim of this study was to determine the full set of elastic constants of the layers of three-layer particleboards assuming orthotropic anisotropy of these layers.

\section{Materials and methods}

Typical commercial three-layer particleboards with the thickness of $18 \mathrm{~mm}$, bonded with UF resin meeting the re- 
Fig. 1 Separated layers of particleboard and principal axes of the elasticity

Abb. 1 Deck- und

Mittelschichten der Spanplatte

sowie Achsen der

Elastizitätskonstanten

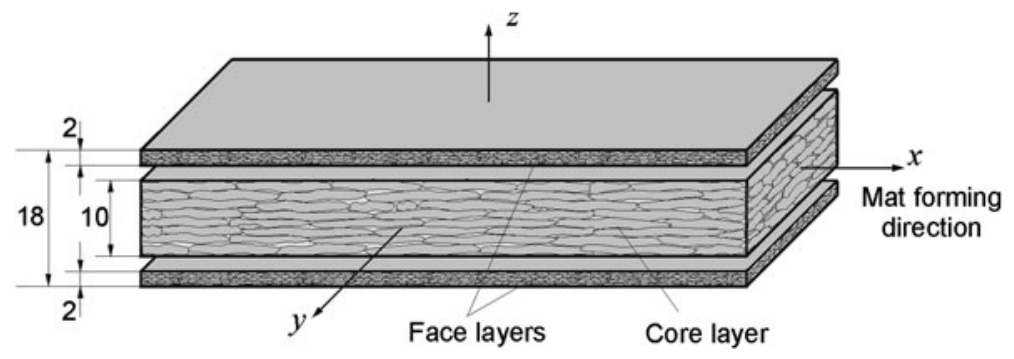

quirements of EN 312, grade P4 were used in this study. The particleboards were obtained from various manufacturers. Their density ranged from 676 to $714 \mathrm{~kg} / \mathrm{m}^{3}$.

Three-layer particleboard, see Fig. 1, can be regarded as an orthotropic body (Bodig and Jayne 1993; Bucur et al. 1998). The principal axes of elasticity have the following directions: $x$-mat forming direction, $y$-perpendicular to the mat forming direction, and $z$-perpendicular to the board. The set of elastic constants: three Young's moduli, six Poisson's ratios and three shear moduli were determined for both the face and core layers.

The method of compressing test specimens and measuring their elastic strains by means of electric resistance gauges was used. Six types of specimens $60 \mathrm{~mm}$ long, $30 \mathrm{~mm}$ wide and $20 \mathrm{~mm}$ thick were employed. They were glued from core and face strips separated from particleboards by appropriate mechanical processing. The thickness of the strips was $2 \mathrm{~mm}$ and $10 \mathrm{~mm}$ for the face and core layer, respectively, see Fig. 1.

\section{Results}

The effect of the particleboard manufacture on the layer elastic constants was evaluated by analysis of variance. There were no statistically significant differences (at the 5\% significance level) in these constants among the tested particleboards. Consequently, it was decided to average each elastic constant based on the total results for all particleboards. The average elastic constants of the particleboard layers as orthotropic materials are presented in Table 1.

For both the face and core layers the modulus $E_{y}$ in the perpendicular direction is, as expected, lower than the modulus $E_{x}$ in the mat forming direction. The modulus $E_{y}$ amounts to $86 \%$ and $87 \%$ of the modulus $E_{x}$ for the face and core layers, respectively. The modulus $E_{z}$ in the direction perpendicular to the layer plane is very low amounting only to $11 \%$ and $13 \%$ of the modulus $E_{x}$ for the face and core layers, respectively. This comparison proves strong anisotropy of the layers in the $x z$ plane, i.e., the plane perpendicular to the plane of layers.

The moduli $G_{x z}$ and $G_{y z}$ in the planes perpendicular to the layer plane are much smaller than the modulus $G_{x y}$ in
Table 1 Average elastic constants and density of particleboard layers Tab. 1 Durchschnittliche Elastizitätskonstanten und Dichte der Mittel- und Deckschichten

\begin{tabular}{lllll}
\hline Elastic constant & \multicolumn{2}{l}{ Face layer } & \multicolumn{2}{l}{ Core layer } \\
\hline$E_{x}(\mathrm{GPa})$ & 4.43 & $(0.47)$ & 1.82 & $(0.14)$ \\
$E_{y}(\mathrm{GPa})$ & 3.82 & $(0.33)$ & 1.59 & $(0.20)$ \\
$E_{z}(\mathrm{GPa})$ & 0.49 & $(0.06)$ & 0.23 & $(0.02)$ \\
$G_{x y}(\mathrm{GPa})$ & 1.61 & $(0.14)$ & 0.73 & $(0.07)$ \\
$G_{x z}(\mathrm{GPa})$ & 0.34 & $(0.04)$ & 0.19 & $(0.02)$ \\
$G_{y z}(\mathrm{GPa})$ & 0.33 & $(0.04)$ & 0.18 & $(0.01)$ \\
$v_{x y}$ & 0.27 & $(0.04)$ & 0.28 & $(0.06)$ \\
$v_{y x}$ & 0.23 & $(0.03)$ & 0.23 & $(0.04)$ \\
$v_{x z}$ & 0.35 & $(0.06)$ & 0.34 & $(0.05)$ \\
$v_{y z}$ & 0.35 & $(0.07)$ & 0.30 & $(0.06)$ \\
$v_{z x}$ & 0.04 & $(0.01)$ & 0.04 & $(0.01)$ \\
$v_{z y}$ & 0.05 & $(0.01)$ & 0.05 & $(0.01)$ \\
Density $\left(\mathrm{kg} / \mathrm{m}^{3}\right)$ & 952 & $(23)$ & 596 & $(14)$ \\
\hline
\end{tabular}

Numbers in parentheses show standard deviations

the layer plane. They amount only to $21 \%$ and $20 \%$ of the modulus $G_{x y}$ for the face layer, and to $26 \%$ and $25 \%$ of the $G_{x y}$ for the core layer.

The Young's moduli of the core layer range from $41 \%$ to $47 \%$ of those of the face layer. The shear moduli of the core layer range from $45 \%$ to $55 \%$ of those of the face layer. The mean density of the core layer is $63 \%$ of that of the face layer. The relative differences between elastic moduli of the core and face layers, particularly between the Young's moduli, are greater than the difference between the densities of these layers. One can conclude that the elastic moduli of the particleboard layers are not proportionate to their densities.

The differences between the Poisson's ratios of the core and face layers are low, and amount most often to a few percent. The Poisson's ratios of the face layer are usually greater. It is worth noting that the Poisson's ratios $v_{x z}$ and $v_{y z}$ related to the transverse layer planes achieve greater values both for the face and the core layer than the Poisson's ratio $v_{x y}$ related to the layer plane.

Acknowledgement This work was supported by grant N N309 116837 from the Polish Ministry of Science and Higher Education. 
Open Access This article is distributed under the terms of the Creative Commons Attribution Noncommercial License which permits any noncommercial use, distribution, and reproduction in any medium, provided the original author(s) and source are credited.

\section{References}

Bodig J, Jayne BA (1993) Mechanics of wood and wood composites. Krieger, Malabar, $712 \mathrm{pp}$

Bucur V, Ansell MP, Barlow CY, Pritchard J, Garros S, Deglise X (1998) Physical methods for characterizing wood composite panel products. Holzforschung 52:553-561
Dueholm S (1976) Untersuchungen zum Deformationsverhalten von geschichteten Holzwerkstoffplatten unter Klimaeinwirkung. Thesis, University of Hamburg, 162 pp (in German)

Geimer RL, Montrey HM, Lehman WF (1975) Effects of layer characteristics on the properties of three-layer particleboards. For Prod J 25:19-29

Keylwerth R (1958) Zur Mechanik der mehrschichtigen Spanplatte. Holz Roh-Werkst 16:419-430 (in German)

May HA (1983) Zusammenhänge zwischen Eigenschaften, Rohstoffkomponenten und dem Dichteprofil von Spanplatten. Holz RohWerkst 41:369-374 (in German)

Wilczyński A, Kociszewski M (2007) Bending properties of particleboard and MDF layers. Holzforschung 61:717-722 